\title{
Qualitative, Patient-Centered Assessment of Muscle Cramp Impact and Severity
}

\author{
Hans D. Katzberg, Vera Bril, Sarah Riaz, Carolina Barnett
}

\begin{abstract}
Background: There is an urgent need for new therapeutic options to treat muscle cramps; however, no patient-reported measures exist that capture the entire cramp experience. We conducted a qualitative study to assess the experience of patients suffering muscle cramps, aiming to understand what factors determine the impact cramps have in patients' lives to guide the development of a patient-centered outcome measure of cramp severity and impact. Methods: We enrolled patients with cramps due to several etiologies, including motor neuron disease, pregnancy-induced cramps, cirrhosis and hemodialysis, and idiopathic and exercise-induced cramps. Patients participated in semistructured interviews about their experiences with muscle cramps and their responses were recorded and transcribed. Data were analyzed with content analysis using data saturation to determine the sample size. We subsequently developed a conceptual framework of cramp severity and overall cramp impact. Results: Ten patients were interviewed when data saturation was reached. The cramp experience was similar across disease and physiological states known to cause muscle cramps. The main themes that compose the overall cramp impact are cramp characteristics, sleep interference, daytime activities interference, and the effect on mental health. Conclusions: This framework will be used to develop a patient-reported outcome of cramp severity and impact.
\end{abstract}

RÉSUMÉ : Évaluer qualitativement l'impact et la gravité des crampes musculaires tout en étant axé sur les patients qui en souffrent. Contexte : Il existe un besoin urgent de mettre en œuvre de nouvelles options thérapeutiquespour le soulagementdes crampes musculaires. Cela dit, aucun patient qui en souffre ne semble avoir fait état d'optionstenant compte de la totalité de leurexpérience. À cet égard, nous avons effectué une étude qualitative afin justement de mieux cerner l'expérience de ces patients et de comprendreles facteurs qui déterminentl'impact que les crampes peuvent avoir dans leur vie. Nous voulons du coup orienter l'élaboration d'indicateursaxés sur les patients eux-mêmes, indicateurs visant à mesurer l'impact et la gravité de leurs crampes musculaires. Méthodes : Nous avons recruté des patients atteints de crampes musculaires en raison de plusieurs étiologies, par exemple des pathologies du motoneurone, des crampes liées à une grossesse, des cas de cirrhosenécessitant une hémodialyse, des crampes idiopathiquesou déclenchées par l'exercice, etc. Les patients recrutés ont participé à des entrevues semi-structurées portant sur leur expérience en lien avec des crampes musculaires, leurs réponses étant enregistrées et par la suite transcrites. En plus déterminer la taille de notre échantillon à l'aide de la saturation de données, nous avons ensuite analysé ces dernières au moyen de la méthode d'analyse de contenu. Enfin, nous avons élaboré un cadre conceptuel de la gravité des crampes musculaires et de leur impact général. Résultats : Une fois nos données saturées, dix patients ont été interviewés. Les expériences liées à leurs crampes se sont révélées comparables peu importe les maladies et les états physiologiques. Parmi les principaux aspects caractérisant l'impact général des crampes, mentionnons les suivants : les caractéristiques des crampes, les perturbations du sommeil qu'elles entraînent, leur interférence dans des activités de jour et leurs effets sur la santé mentale. Conclusions : Ce cadre de référence sera utilisé pour élaborer un outil mesurant la gravité et l'impact des crampes musculaires, et ce, en fonction de l'apport des patients eux-mêmes.

Keywords: Muscle cramps, Neuropathy, Charley Horse, Qualitative, Cramp

doi:10.1017/cjn.2019.286

Can J Neurol Sci. 2019; 46: 735-741

\section{INTRODUCTION}

Muscle cramps are a common neurological symptom ranging in severity from a mild nuisance to profound disability for some people. ${ }^{1}$ Evaluation for potential physiological stressors including pregnancy, renal dysfunction, and cirrhosis, and neuromuscular conditions such as neuropathy, radiculopathy, and motor neuron disease should be performed as these conditions can all lead to muscle cramps. ${ }^{2}$ The prevalence of muscle cramps ranges from $37 \%$ to $95 \%$ depending on the patient group studied. ${ }^{3-5}$ There is currently a need for new therapeutic options to treat muscle cramps, particularly as the restriction of quinine sulfate for use in muscle cramps in the USA by the Food and Drug Administration has created a gap in therapeutic options for this potentially disabling symptom. ${ }^{6}$ In addition, the development of a reliable and validated tool to assess the severity and impact of cramps in clinical practice as well for clinical trials is also needed. $^{2}$

Although cramp frequency has been used most commonly as a primary outcome measure in muscle cramp trials, a validated assessment scale that factors in not only cramp frequency but also duration and pain intensity may be a more optimal way to assess muscle cramps and measure clinically relevant change. ${ }^{7}$

From the Division of Neurology, University Health Network, University of Toronto, Toronto, Ontario, Canada

Received May 28, 2019. Final Revisions Submitted August 5, 2019. Date of Acceptance August 15, 2019.

Correspondence to: Hans D. Katzberg, Toronto General Hospital/UHN, 200 Elizabeth Street, 5ES-306, Toronto, Ontario M5G 2C4, Canada. Email: hans.katzberg@utoronto.ca 
Our own data evaluating cramps in patients with polyneuropathy have shown that parameters such as pain, duration of muscle cramps, and cramp frequency occur across a range of severities. ${ }^{8}$ Based on these data, we hypothesized that for patients suffering from cramps, there are more factors involved in cramp severity and impact than just cramp frequency. Therefore, we aimed to assess the experiences of patients suffering from muscle cramps to develop a framework of cramp impact, to guide the development of a patient-centered measure of the overall cramp impact. We selected a group of heterogeneous conditions which have been known to cause neurogenic muscle cramps in order to evaluate whether the cramp experience is similar across disease and physiological states. In order to evaluate the cramp experience from the patient perspective, we have elected to use a qualitative approach based on emerging research supporting the use of patient-reported outcome measures for analysis of qualitative data. ${ }^{9,10}$

\section{Methods}

This is a qualitative study where we interviewed patients to understand their experiences regarding cramps. The interview script (included in supplementary materials) was semistructured, contained a combination of general and more focused questions taken from a town hall performed in 2014 with a group of six patients with muscle cramps (data not shown). We used content analysis, which is a systematic way of identifying themes in qualitative data and all efforts were made to maintain consistency and neutrality across patients in the collection and analysis of the data as recommended in the Professional Society for Health Economics and Outcomes Research Patient-Reported Outcomes (ISPOR PRO) Good Research Practice guidelines. ${ }^{9}$ Data transferability was achieved by including a broad spectrum of physiological and disease states leading to muscle cramps, with a range of cramp frequencies and severities in an effort to maintain the optimal credibility component of the qualitative analysis. Raw qualitative data from patient interviews were transcribed, grouped into common phrases, and added to a deidentified database of grouped data. These phrases were reviewed in real time after each patient interview and were continuously grouped into themes until no additional patient themes were identified in order to reach data saturation.

\section{Patient Selection}

We used purposive sampling to enroll patients with different causes of cramps, since our aim is to develop a cramp measure that can be used regardless of the cramp etiologies, such as idiopathic, motor neuron disease, hemodialysis, and pregnancyrelated cramps. Additionally, we enrolled patients with different degrees of cramp severity to capture the breadth of presentation. We recruited patients from the neuromuscular, amyotrophic lateral sclerosis (ALS), renal, liver, and maternal clinics at the University Health Network/Mout Sinai Hospital. There is no specific sample size for qualitative studies; however, it is usually accepted that when no new codes are generated with successive interviews, the sample size is sufficient. ${ }^{11}$ Therefore, we used data saturation to determine when to stop new interviews. All patients consented to the study which was approved by the local ethics committee, and the study followed the ethical principles set out in the Declaration of Helsinki.

\section{INTERVIEWS AND ANALYSIS}

Patients' interviews followed a semistructured format that was designed to elicit patients' experiences regarding cramps. All interviews were conducted by one investigator (SR) and were recorded and transcribed verbatim. Transcripts were then imported into HyperRESEARCH (version 3.5; Researchware, Inc., Randolph, MA, USA), a software for qualitative analysis. Interviews were analyzed through content analysis, ${ }^{12}$ where words and phrases with similar meanings are coded together, using line-by-line coding. The first three interviews were coded by three investigators (SR, CB, HK) for consistency and a code book was developed. The following interviews were coded by a single investigator (SR), using the original code book as reference and incorporating new codes that appeared. Investigators met periodically to discuss the new codes generated and to determine when codes needed to be merged and to discuss potential biases. In this way, the analysis was ongoing as new interviews were being performed. Similar codes were grouped into themes that were further divided into subthemes if necessary, resulting in a framework of the overall impact of muscle cramps.

\section{ReSUlts}

Cramp themes and subthemes were monitored and grouped throughout the patient interviews, and saturation was reached by patient 9, with redundant themes identified with patient 10 leading to study end and the inclusion of these 10 patients in the study. Six women and four men, with an average age of 52 (range 27-75 years), were included, and the interviews ranged from 18 to $47 \mathrm{~min}$ and the average duration of cramps was 3.8 years. The patients had varied cramp etiologies and included two patients with idiopathic muscle cramps, one patient with ALS, one patient with pregnancy-induced cramps, two patients with diabetes (one who also had cirrhosis, neither with neuropathy), two patients with cirrhosis (including the one patient with diabetes), one patient with chronic renal failure on dialysis, and two patients with exercise-induced cramps. Clinical and additional demographic characteristics are shown in Table 1.

The actual description of the cramp itself did not vary much among patients, and most patients described muscle cramps as a tightening of the muscles such as this patient: "muscles are rock solid and I can't move" (P2, age 50), consistent with the accepted definition of neurogenic muscle cramps, where neurogenic firing causes "all-or-nothing" contraction of a muscle or muscle group.

We identified four main themes: (1) cramp characteristics, (2) sleep-related effects, (3) effects on daytime function, and (4) mental health concerns related to cramps. Cramp severity relates to the characteristics of the cramps which determine how severe they are in each individual patient and includes subthemes including cramp location, frequency, intensity, and duration of the muscle cramps. Cramp impact includes how cramps affect daily life activities and the overall health and subthemes here include the effects of muscle cramps on daytime activities such as ability to work and effects on mobility and functioning and subthemes related to nighttime activities, including disruption of sleep and subsequent development of excessive daytime sleepiness. These themes and subthemes are graphically depicted in Figure 1. The following represents an overview of each theme with examples of its subthemes with appropriate quotes from 
Table 1: Patient demographics

\begin{tabular}{|c|c|c|c|c|c|}
\hline Number & Diagnosis & Gender & Age (years) & $\begin{array}{c}\begin{array}{c}\text { Duration of cramps } \\
\text { (years) }\end{array} \\
\end{array}$ & Comments \\
\hline P. 1 & Idiopathic cramps & Male & 28 & 4 & \\
\hline P. 2 & Idiopathic cramps & Female & 50 & 3 & \\
\hline P. 3 & $\begin{array}{l}\text { Diabetes + liver } \\
\text { cirrhosis }\end{array}$ & Male & 58 & 3 & $\begin{array}{l}\text { Type } 2 \text { diabetes on } \\
\text { insulin Nonalcoholic } \\
\text { steatohepatitis-related } \\
\text { cirrhosis } \\
\text { and hepatocellular } \\
\text { carcinoma }\end{array}$ \\
\hline P. 4 & Diabetes & Female & 70 & 6 & $\begin{array}{c}\text { Type } 2 \text { diabetes on oral } \\
\text { hypoglycemic agents }\end{array}$ \\
\hline $\begin{array}{l}\text { P. } 5 \\
\end{array}$ & $\begin{array}{l}\text { Amyotrophic lateral } \\
\text { sclerosis }\end{array}$ & Male & 55 & 1 & $\begin{array}{l}\text { Duration of initial } \\
\text { leg weakness } 3 \text { months } \\
\text { prior to cramps }\end{array}$ \\
\hline P. 6 & Liver cirrhosis & Female & 75 & 0.5 & $\begin{array}{l}\text { Nonalcoholic } \\
\text { steatohepatitis-related } \\
\text { cirrhosis }\end{array}$ \\
\hline P. 7 & Pregnancy & Female & 27 & 0.5 & $\begin{array}{l}\text { Gestational age } \\
34 \text { weeks } 4 \text { days. Two } \\
\text { previous gestations } \\
\text { and successful } \\
\text { pregnancies }\end{array}$ \\
\hline $\begin{array}{ll}\text { P. } 8 \\
\end{array}$ & Chronic renal failure & Female & 65 & 7 & \begin{tabular}{|c} 
On dialysis for 11 years \\
due to renal failure
\end{tabular} \\
\hline P. 9 & $\begin{array}{l}\text { Exercise-induced } \\
\text { cramps }\end{array}$ & Male & 48 & 4 & Otherwise healthy \\
\hline P. 10 & $\begin{array}{l}\text { Exercise-induced } \\
\text { cramps }\end{array}$ & Female & 40 & 9 & Otherwise healthy \\
\hline
\end{tabular}

patients. Additional quotes supporting the various cramp themes are listed in Table 2.

\section{Main Theme 1: Cramp Characteristics}

One of the main themes identified is cramp severity, which defines the different aspects of the cramp episodes according to the patients. These aspects - subthemes - are cramp intensity, frequency, duration, location, and cramp-related injury, which are described in detail below.

\section{Subtheme: Cramp Pain Intensity}

This refers to the degree of pain or discomfort experienced by patients during a cramp episode. This includes ranges of intensity of the individual muscles cramps, from mild such as: "not so bad, I can usually stand up and walk them out" (P1, Age 28), to severe pain, reflected in these quotes: "hideous. It hurts too much to cry" (P2, Age 50), and that "I imagine that the pain is as severe as having a heart attack" (P4, Age 70).

\section{Subtheme: Cramp Frequency}

Patients consistently reported the frequency of muscle cramps as an important factor. Patients reported a varied range in frequency, from infrequent: "maybe a couple days a week" (P1, Age 28) to daily to several times per day, such as in the following example: “... sometimes occurring three to four per night, so very frequently" (P7, Age 27). In addition, many patients reported fluctuations in the cramp frequency: "Sometimes, every day, it can happen three to four times in-between. And sometimes, I take it one at a time" (P3, Age 58).

\section{Subtheme: Cramp Duration}

Many patients commented on the variable duration of the cramps, but most frequently these were described spanning over a few minutes, for example: “... it depends, when they're bad ones, they'll last a couple of minutes, Not so bad, I can usually stand up and just walk them out, they last 30 seconds" (P3, Age 58). A few patients experienced longer cramp episodes, with one patient stating cramps "I would say, generally speaking, when you get a bad cramp, it lasts for about 15, 20 minutes" (P6, Age 75).

\section{Subtheme: Cramp Location}

Most patients experienced cramps in the calves and in the distal lower extremity muscles, for example: "So, it's all between my ... below my knee and my calf, so it's all the backside of my leg" (P7, Age 27). In some cases, progression of the disease caused dispersion of the cramps in the body, as this patient describes: "After about the first year of just the feet, the cramps started to ascend, I started getting them in my calves, and then after a while of that, I was getting them in my thighs as 


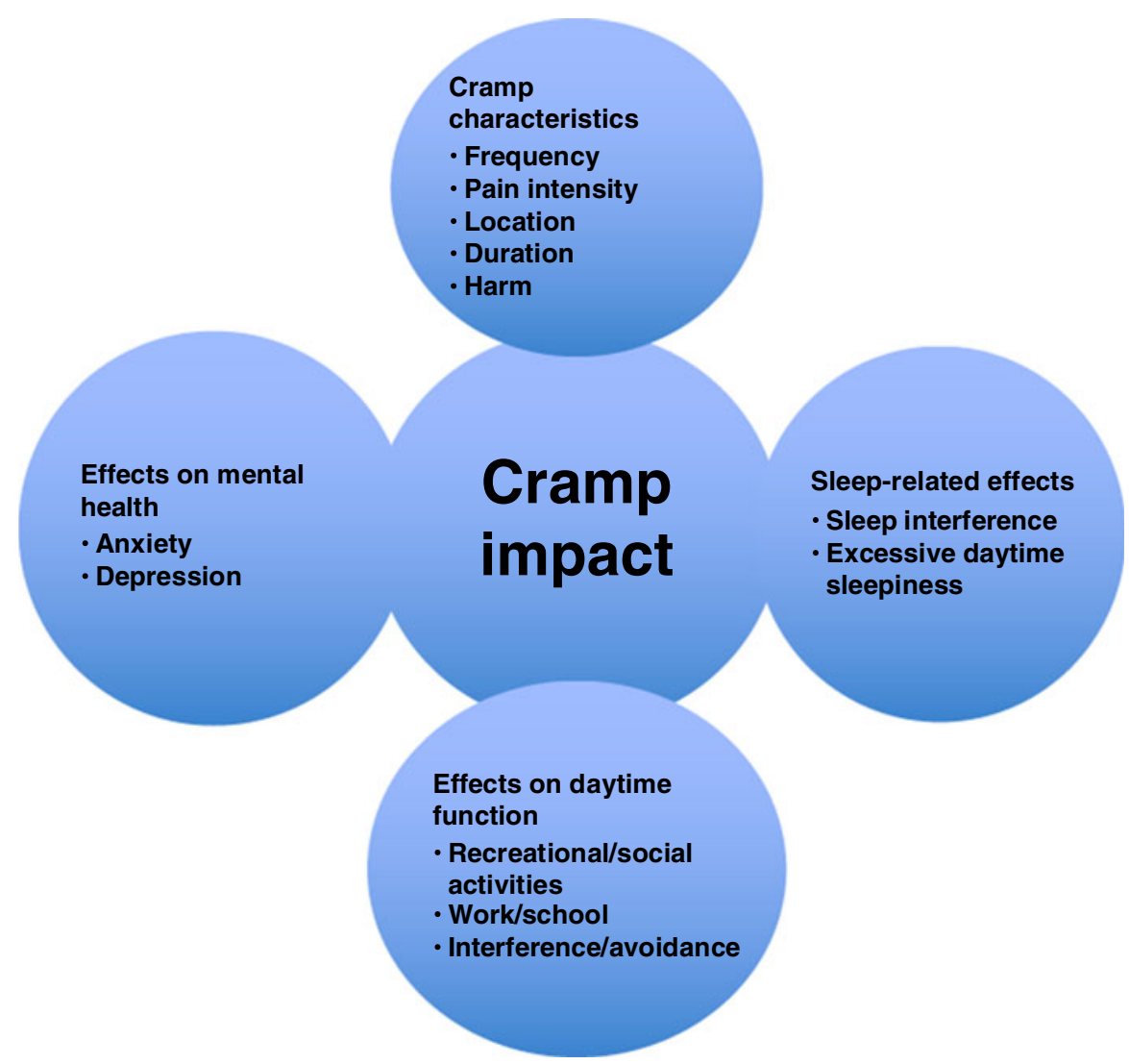

Figure 1: Major and subdomain themes contributing to cramp impact.

well" (P1, Age 28). Overall, there was a range of locations that patients described to experience muscle cramps, including the neck, face, abdomen, arms, and back: "Cramps involve every muscle including abdomen and neck, I would say every muscle. I remember my abdomen cramping before. When I had it worse when I was in [], my pectoral muscles were cramping. They were cramping and I wasn't even utilizing them. I guess I was because when you climb hills, right, you have a lot of movement like that" (P9, Age 48). Or in this case: “... If I were to laugh, this whole thing could go into a huge cramp. The cramps are now coming up into my neck and in my tongue" (P4, Age 70). Some patients described that when cramps occurred in multiple body areas, the overall cramp experience was more severe, such as this patient: "It would usually start in one area and then it would start to become more systematic, where it would go from my quads to my hamstrings to my calves, and then literally at the worst of times I'd have almost like a full body cramp" (P9, Age 48).

\section{Subtheme: Harm from Muscle Cramps}

Some patients also described occasions when a cramp resulted in harm or put them in a position with risk of harm. For example: "When I' $m$ in the pool, sometimes it's very helpful but I cramp in the pool as well. I'm only waist deep because I'm just there to try and give my muscles some sense of buoyancy or something. But when I cramp in the pool, I can't get out of the pool because I can't lift my leg to take the step up. And the steps are not that deep; they're maybe three, four, five centimetres high" (P2, Age 50). The majority of these experiences revolved around cramps happening in water, such as potential incapacitation and drowning if cramps occurred in a pool or tub. For example: "I won't go into any open water swimming over a 2 kilometre thing, because if you cramp in the water, which I have cramped in the water before, right, on a long swim, if you cramp in the water, it's dangerous, especially the way I cramp. I try now to stay away from things that can put me in a vulnerable position when I cramp" (P8. Age 65). A few patients with severe muscle contractions due to cramps experienced actual harm with one patient tearing a knee ligament: "Because the cramp had gotten so bad one night, I actually, it pulled a ligament in my knee, so they took me off work" (P1, Age 28).

\section{Main Theme 2: Sleep-Related Effects}

This relates to the nocturnal cramps that many patients experienced and that interfere with sleep and even wake patients from sleep. Patients also commented on the sequelae from sleep disruption, namely, excessive daytime sleepiness and poor functioning in the day from this symptom.

Many patients reported sleep disruption, one cause being predominant nocturnal cramps, such as this patient: "So, for 2012, it was happening, as I said, probably three or four times a week, at night. Sometimes during the day but mostly at night and I couldn't sleep. And there's nothing I can do" (P2, Age 50). Patients reported nocturnal cramps even during sleep "from a dead sleep, when I'll just wake up in screaming pain" (P1, Age 28). Or "And usually they'd come on, most of the time in the middle of the night, when I was asleep ... and I would be just in a 


\section{Table 2: Additional quotes}

\begin{tabular}{l} 
Cramp severity \\
"I would step out because the pain is so excruciating, I feel like my leg is being cut." (P7) \\
"literally you'll see me, it's like a comedy show. I'll be sitting on the road for a minute or \\
two, quads contracting, it's almost like I've been shot in the legs." (P8) \\
"Last time, when I have ... complete, all my body, I cannot move it. It was very painful. \\
I feel my hands, my legs, altogether. And I cannot move them. It was a lot of pain. I \\
called 911 and they took me to the hospital ..." (P3) \\
"But the worst cramps I had were in my legs. The calves, the ankles and sometimes my \\
quads, is it? My hamstrings, quads and they were bad, very bad." (P5) \\
"Sometimes I'll be on the bike and I'll get cramps in my arms, which really shouldn't be \\
happening... But, it's strange, I can have areas of cramps in my chest, where my chest \\
will literally cramp up, my pecs will cramp up." (P8) \\
"It really varied. Sometimes, I could get rid of it fairly quickly. Other times, it would last \\
10 minutes." (P6) \\
\hline Sleep-related effects \\
"I might get two hours of sleep a night, some nights I don't sleep at all." (P1) \\
"Well, because it wakes me up from sleep ... and it's really painful and I feel like I \\
cannot move my leg, and it's immediate. It just wakes me up from sleep, and I have \\
to jump out of my bed and step on my feet a few times in order for it to go away. I \\
can't even move it, it's very painful." (P7) \\
\hline Daytime effects \\
"For work, I was a, I'm a [physically demanding job] and I don't play sports ... it's \\
certainly worse on especially difficult days. If it's an especially hard job, and I'm \\
much more active, then it's going to happen more." (P1) \\
can't do anything that requires sitting, so it's huge." (P2) \\
mould I do if my legs went into cramps." (P4) \\
"Whental health effects \\
mentally and cardiovascularly able to continue on, but you can't. That can be, at the \\
\hline
\end{tabular}

panic to get out of bed and try and stretch them out. But it would take probably a good 15 minutes to stretch it out, to the point where I was comfortable going back to bed" (P5, Age 55). Additionally, nocturnal cramps could happen frequently such as: "every night, but some nights they wake me up four to five times a night. Sometimes they wake me up once or twice" (P7, Age 27).

Another sleep-related effect includes the effects on daytime wakefulness, manifesting as excessive daytime sleepiness, for example: "I wake up two or three times and, maybe, I'm not sleeping at all because if you have interruption of sleeping, you get tired in the morning. Sometimes, I call in sick. When I feel tired, I cannot go to work" (P3, Age 58).

\section{Main Theme 3: Interference with Daily Life Activities}

Patients in our cohort consistently stated that when cramps occur, they could interfere with activities of daily life as well as participation in work, school, and leisure activities. These specific subthemes are described below.

\section{Subtheme: Effects on Work/School}

Multiple patients identified that cramps affected their work for different reasons, for example, due to poor sleep: "I might get two hours of sleep a night, some nights I don't sleep at all. So it certainly affects me during the day, I'm more irritable, just not as focused at work" (P1, Age 28). Additionally, for some patients who work in an office, sitting for long periods was difficult due to muscle cramps: "I also get the cramping after I've been sitting not even an extended period. Just five minutes and that's it. That's all my body can stand before I start to get spasming, which leads to cramping ... I just can't sit. When I'm at work, I need a standing work station" (P2, Age 50). In contrast, other patients with cramps triggered by physical activities such as walking or sustained hand labor were affected if their work required such activities. For example: "Sometimes, when I do my work, sometimes, the cramps happen to my hand. I cannot hold the thing. So, I just leave my work and go somewhere, relaxing myself. And then, I go back again to continue" (P3, Age 58).

Finally, one patient who suffered an injury due to a cramp had to take time off work: "I've never missed work from it until recently when it actually injured me" (P1, Age 28).

\section{Subtheme: Effects on Leisure Activities}

Other activities identified to be affected by muscle cramps included social events and sports, which are often avoided if patients expect that cramps will occur during the activity. One patient with muscle cramps stated that "I can't sit, go to a movie, sit in a movie theatre or go to the ballet, which may seem like a minor issue for some people but it killed my quality of life" (P2, Age 50), and a similar description by a different patient: "And because of the cramps, I was afraid that if I got into one there, I wouldn't be ... I didn't want to be yelling during a performance. So, we gave the tickets away. So, it is limiting that way" (P6, Age 75). And from the same patient: "I'm not a good knitter but I like to knit a bit just to pass the time. Occasionally, knitting would bring on ... I would think, okay, now I can't do it anymore because the hand starts to cramp."

\section{Subtheme: Avoidance Prevention or Modification of Activities}

In addition to direct interference with leisure or work activities, muscle cramps or cramp pain led some patients to avoid activities or cease activities due to the concern for development of muscle cramps during these activities. For example, one patient avoids social activities due to cramps: "my social life sometimes because on nights where it's really bad, I won't even go out and see anybody" (P1, Age 28). Work avoidance can also occur, with patients stating that "Sometimes, I called in sick, sometimes, because, sometimes, the pain is still in my legs and these things. Sometimes, I call in sick and relax because I'm afraid that it will happen to me in the work" (P3, Age 58). For patients with exercise-induced cramps, they sometimes reduced their exercise load to prevent cramps: "It can limit sometimes how much I exercise, because I'm concerned I might get a cramp" (P10, Age 40).

\section{Main Theme 4: Mental Health Effects}

Some patients also noticed that cramps not only affected their physical well-being but also their mental health. One patient stated: "Mood, for sure, especially, like I said, when I'm not sleeping so much, I'm not the jovial human being that you see in front of you today, so well put together. Certainly I try not to let it affect me, but I know, other times I have a shorter temper, just don't feel like talking to anybody" (P1, Age 28). One patient 
described the worry about a cramp attack as: "It's terrifying because when you know it's starting, you try to ... And when I can see that I've started ... I'm patient with the spasms, I'm patient with them because to become upset, it makes it worse" (P4, Age 70). "If I feel something that might be a cramp, it makes me nervous. In that way, it kind of affects me, because in the back of your head you're worried a little bit that you might get a cramp" (P10, Age 40).

\section{Discussion}

Patients in our cohort experienced a wide spectrum of different cramp frequencies, severities, locations, and durations as well as medical, neurological, and physiological etiologies for muscle cramps. In spite of these differences, patient interviews yielded common themes raised by patients and clients with regard to the cramp experience. One main theme included a description of the cramp characteristics which patients found important including cramp intensity, frequency, duration, and location. The second main theme included the impact of cramps on patient activities occurring during daytime and nocturnal times of day. Cramp impact during the day including cramps affecting exercise, work, school, and social activities, as well as potential harm or injury occurring from muscle cramps and cramp impact at night interfered with sleep itself and was found to cause excessive daytime sleepiness in some patients. This conceptual separation can also be useful to independently assess severity of muscle cramps in patients who experience cramps: in patients who have them throughout the day and night or those with predominantly nocturnal leg cramps an entity common in the general population and a major component of those with idiopathic muscle cramps. ${ }^{13-15}$ Finally, patients also identified the effects that muscle cramps have on mental health, including negative effects on mood and in creating worry and anxiety.

To date, most systematic assessments of muscle cramps for clinical trials have used cramp frequency as the primary or sole measure of the how muscle cramps affect patients. ${ }^{7,16}$ Similarly, treatment effects for agents used to treat muscle cramps have used a reduction in cramp frequency or number of cramp days or nights are a measure of response to treatment. According to the current interviews, this is not the sole aspect of the muscle cramps which are disruptive to patients. There does appear to be emphasis placed particularly on cramp pain intensity, with a distribution which ranges from a mild ache to descriptors usually used in conditions such as myocardial infarction or subarachnoid hemorrhage. Duration of muscle cramps and location of muscles in the arms, legs, trunk, and even neck and face were also identified as key cramp characteristics but were less commonly mentioned. Cramp duration, in particular, can be difficult to accurately assess as postcramp residual pain is not characteristically considered part of an actual muscle cramp. Although uncommon, there were patients in our cohort who experience not only frequent cramps but also cramps occurring in multiple locations outside the more common toes, feet, and cramps. The patients in our group experiencing muscle cramps in the feet, legs, thighs, back, neck, face, arms, and torso also stated that there was a relationship between cramps in multiple locations affecting their cramp experience negatively and affecting more activities, particularly those requiring hand dexterity and other higher level functions such as speaking, eating, and breathing.
There have been other efforts at capturing the cramp characteristics mentioned above in a comprehensive cramp questionnaire. Chatrath et al. recognized the multifaceted nature of the cramp experience and captured all of the aspects mentioned above in their assessment of muscle cramps in patients with cirrhosis. ${ }^{17}$ Other groups also assessed patients with cirrhosis and muscle cramps and found that intensity, duration, and frequency of muscle cramps improved in response to treatments including baclofen, possibly on the basis of peripheral nerve hyperexcitability. ${ }^{18,19}$ Our previous studies in patients with diabetes and polyneuropathy also captured the full experience of cramp characteristics identifying all aspects mentioned above including aspects related to mental health, suggesting a signal that differs across disease states. ${ }^{8,20}$ It is important for clinicians to be aware that when patients describe pain in certain neurological syndromes, particularly motor predominant neuropathic syndromes such as ALS, they are often referring to muscle cramps, which account for pain in $63 \%$ of patients with ALS and is similar to the patients with motor neuron disease and neuropathy in our cohort. $^{5,16,21-22}$ Our previous studies of patients with polyneuropathy did identify that muscle cramps were as prevalent and selfidentified as disabling as neuropathic pain, the more commonly recognized symptom of polyneuropathy by clinicians. ${ }^{8}$

The current results and observations mirror our clinical experience that cramp characteristics such as frequency and intensity are key to evaluating the full cramp experience. In addition, our study includes a variety of clinical conditions and physiological states which have in common muscle cramps as a prominent symptom, including pregnancy, renal failure, and hemodialysis ${ }^{23-25}$ among other conditions mentioned above including neuropathy and cirrhosis. Although the exact duration of a cramp can be difficult to confirm due to the presence of postcramp pain, this was also felt to be an important feature to patients and left in the final list of subthemes. Although most commonly cramps occur in the lower extremity muscles such as the calf muscles, patients consistently identified that the exact location and number of places in the body that experience cramping was also an important part of the experience. These data thus do provide evidence that location and duration of muscle cramps should merit further study and evaluation in any effort to comprehensively evaluate muscle cramps. The answers provided were consistent across the different groups of patients interviewed regardless of etiology, and further study is also needed to evaluate how the different themes and subthemes captured inter-relate and influence one another in patients experiencing cramps, as this was not the goal of this particular study.

Our methods included a data saturation method where interviews were continued until no additional themes were identified regarding the cramp experience. In our study, this required 10 interviews, and as such an intrinsic limitation of this methodology includes missing some cramp features that would be captured by interviewing more patients with muscle cramps. In addition, the full cramp experience and cramp experience across multiple disease and physiological states was the goal of the study; however, not all ranges of cramp severity or conditions associated with cramps can be ever captured in a single study, an intrinsic limitation. Finally, there are intrinsic limitations to qualitative analysis, primarily a lack of sequential or hierarchical organization of what themes dominate importance in patients with muscle cramps, which will have to be the subject of subsequent studies. 
In conclusion, this qualitative study provides a unique, patient-centered assessment of the full cramp experience across disease and physiological states. Similar themes relating to cramp characteristics and effects on daytime and nocturnal functioning were identified in most patients. When evaluating cramp characteristics, information about cramp intensity, duration, location, and intensity should be captured in addition to cramp frequency. The effects of muscle cramps on daytime activities, sleep impact, and excessive daytime sleepiness should also be assessed to capture the entire cramp experience. In addition to providing guidance to clinicians and patients looking to evaluate the full cramp experience in clinical practice, it forms the first step in the generation of an assessment tool which can then be validated and tested in patients for eventual use in clinical practice and in clinical trials to measure cramp impact.

\section{ACKNOWLedGements}

This study was supported by a New Initiatives Grant from the Division of Neurology at the University of Toronto

\section{Statement of Authorship}

HK is the primary and corresponding author and participated in the design, data collection, interpretation of data, and writing of the manuscript. SR was responsible for data collection including the patient interviews and data analysis. $\mathrm{VB}$ and $\mathrm{CB}$ were involved in the design of the study as well as the data analysis and writing of the manuscript.

\section{Disclosures}

This study was supported by a New Initiative Grant from the University of Toronto. HD has received consulting and speaking fees from Akcea, speaking fees and travel support from CSL Behring, speaking fees and a clinical grant from Takaeda, consulting fees from Grifols, Terumo and Alexion and serves as the Data Safety Monitoring Board chair for an Octapharma clinical study, all nonrelevant to this study. CB has clinical grants from Grifols, Octapharma, and the Department of Defence and has received financial support for training and consulting from Akcea and Takaeda, all nonrelevant to this study. VB and SR have nothing to disclose.

\section{SupPlementary Material}

To view supplementary material for this article, please visit https://doi.org/10.1017/cjn.2019.286.

\section{REFERENCES}

1. Abdulla AJ, Jones PW, Pearce VR. Leg cramps in the elderly: prevalence, drug and disease associations. Int $\mathrm{J}$ Clin Pract. 1999;53:494-6.
2. Katzberg HD. Neurogenic muscle cramps. J Neurol. 2015;262(8): 1814-21.

3. Naylor JR, Young JB. A general population survey of rest cramps. Age Ageing. 1994;23:418-20.

4. Butler JV, Mulkerrin EC, O'Keeffe ST. Nocturnal leg cramps in older people. Postgrad Med J. 2002;78:596-8.

5. Ganzini L, Johnston W, Hoffman W. Correlates of suffering in amyotrophic lateral sclerosis. Neurology. 1999;52(7):1434-40.

6. Food and Drug Administration, Department of Health and Human Services. Drug products containing quinine; enforcement action dates. Fed Reg. 2006;71:75557-60.

7. Katzberg, HD, Khan AH, So YT. Assessment: symptomatic treatment for muscle cramps (an evidence-based review). Neurology. 2010;74(8):691-6.

8. Maxwell SK, Kokokyi S, Breiner A, et al. Characteristics of muscle cramps in patients with polyneuropathy. Neuromuscular Disorders. 2014; 24(8):671-6.

9. Patrick DL, Burke LB, Gwaltney CJ, et al. Content validity establishing and reporting the evidence in newly developed patient-reported (pro) instruments for medical product evaluation: ISPOR PRO good research practices task force report. Part 1- eliciting concepts for a new PRO instrument. Value in Health. 2011; 15:967-77.

10. Calvert M, Kyte D, Mercieca-Bebber R. Guidelines for inclusion of patient-reported outcomes in clinical trial protocols: the SPIRITPRO extension. 2018;319(5):483-94.

11. Guest G. How many interviews are enough? An experiment with data saturation and variability. Field Methods. 2006;18:59-82.

12. Elo $\mathrm{S}$, Kyngäs $\mathrm{H}$. The qualitative content analysis process. J Adv Nurs. 2008; 62:107-15.

13. Naylor JR, Young JB. A general population survey of rest cramps. Age Ageing. 1994;23:418-20.

14. Jansen PH, Gabreëls FJ, van Engelen BG. Diagnosis and differential diagnosis of muscle cramps: a clinical approach. J Clin Neuromuscul Dis. 2002;4(2):89-94.

15. Gulich M, Heil P, Zeitler HP. Epidemiology and determinants of nocturnal calf cramps. Eur J Gen Pract. 1998;4(3):109-13.

16. Swash M, Czesnik D, de Carvalho M. Muscular cramp: causes and management. Eur J Neurol. 2019;26(2):214-21.

17. Chatrath H, Liangpunsakul S, Ghabril M, et al. Prevalence and morbidity associated with muscle cramps in patients with cirrhosis. Am J Med. 2012;125(10):1019-25.

18. Ng K, Lin CS, Murray NM, et al. Conduction and excitability properties of peripheral nerves in end-stage liver disease. Muscle Nerve. 2007;35:730-8.

19. Elfert AA, Abo Ali L, Soliman S, et al. Randomized placebocontrolled study of baclofen in the treatment of muscle cramps in patients with liver cirrhosis. Eur J Gastroenterol Hepatol 2016; 28(11):1280-4

20. Katzberg H, Kokokyi S, Halpern E, et al. Prevalence of muscle cramps in patients with diabetes. Diabetes Care. 2014;37(1):e17-8.

21. Miller TM, Layzer RB. Muscle Cramps. Muscle Nerve. 2005;32(4): 431-42.

22. Caress JB, Ciarlone SL, Sullivan EA, Griffin LP, Cartwright MS. Natural history of muscle cramps in amyotrophic lateral sclerosis. Muscle Nerve. 2016;53(4):513-7.

23. Lindsay RM, Shulman T, Prakash S, et al. Hemodynamic and volume changes during hemodialysis. Hemodial Int. 2003;7: 204-8.

24. Hensley JG. Leg cramps and restless legs syndrome during pregnancy. J Midwifery Womens Health. 1998;54(3):211-18.

25. Arieff AI. Dialysis disequilibrium syndrome: current concepts on pathogenesis and prevention. Kidney Int. 1994;5:629-35. 